Check for updates

Cite this: RSC Adv., 2019, 9, 3169

Received 29th November 2018

Accepted 10th January 2019

DOI: $10.1039 / \mathrm{c} 8 \mathrm{ra09831j}$

rsc.li/rsc-advances

\section{Intense-pulsed-UV-converted perhydropolysilazane gate dielectrics for organic field-effect transistors and logic gates $\dagger$}

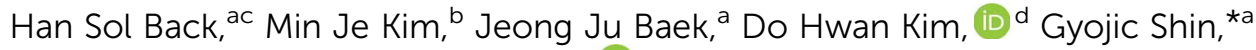 \\ Kyung Ho Choi ${ }^{* a}$ and Jeong Ho Cho iD *e
}

\begin{abstract}
We fabricated a high-quality perhydropolysilazane (PHPS)-derived $\mathrm{SiO}_{2}$ film by intense pulsed UV irradiation and applied it as a gate dielectric layer in high-performance organic field-effect transistors (OFETs) and complementary inverters. The conversion process of PHPS to $\mathrm{SiO}_{2}$ was optimized by varying the number of intense pulses and applied voltage. The chemical structure and gate dielectric properties of the PHPSderived $\mathrm{SiO}_{2}$ films were systematically investigated via Fourier transform infrared spectroscopy and leakage current measurements, respectively. The resulting PHPS-derived $\mathrm{SiO}_{2}$ gate dielectric layer showed a dielectric constant of 3.8 at $1 \mathrm{MHz}$ and a leakage current density of $9.7 \times 10^{-12} \mathrm{~A} \mathrm{~cm}^{-2}$ at 4.0 $\mathrm{MV} \mathrm{cm}{ }^{-1}$. The PHPS-derived $\mathrm{SiO}_{2}$ film was utilized as a gate dielectric for fabricating benchmark $\mathrm{p}$ - and $\mathrm{n}$-channel OFETs based on pentacene and $\mathrm{N}, \mathrm{N}^{\prime}$-dioctyl-3,4,9,10-perylenedicarboximide (PTCDI-C 8 ), respectively. The resulting OFETs exhibited good electrical properties, such as carrier mobilities of 0.16 $( \pm 0.01) \mathrm{cm}^{2} \mathrm{~V}^{-1} \mathrm{~s}^{-1}$ (for the pentacene OFET) and $0.02( \pm 0.01) \mathrm{cm}^{2} \mathrm{~V}^{-1} \mathrm{~s}^{-1}$ (for the PTCDI-C 8 OFET) and an on-off current ratio larger than $10^{5}$. The fabrication of the PHPS-derived $\mathrm{SiO}_{2}$ gate dielectric layer by a simple solution process and intense pulsed UV irradiation at room temperature serves as a novel approach for the realization of large-area flexible electronics in the flexible device industry of the future.
\end{abstract}

\section{Introduction}

Organic electronic devices such as organic light-emitting diodes, ${ }^{1}$ organic solar cells, ${ }^{2}$ and organic field-effect transistors (OFETs) ${ }^{3,4}$ have attracted significant attention because they offer several advantages such as large-area processability, low weight, ease of fabrication processability, and flexibility. In particular, an OFET is a fundamental component in the development of electronic devices such as displays, ${ }^{5}$ smart cards, and radio-frequency identification tags. ${ }^{6,7}$ In the past decade, the electrical properties of OFETs have been improved

${ }^{a}$ Research Institute of Sustainable Manufacturing System, Intelligent Sustainable Materials R\&D Group, Korea Institute of Industrial Technology, Cheonan-si 331-822, Chungcheongnam-do, Republic of Korea. E-mail: gyshin@kitech.re.kr; khchoi@kitech.re.kr

${ }^{b}$ SKKU Advanced Institute of Nanotechnology (SAINT), Suwon 440-746, Republic of Korea

'School of Chemical Engineering, Sungkyunkwan University, Suwon 440-746, Republic of Korea

${ }^{d}$ Department of Chemical Engineering, Hanyang University, Seoul 04763, Republic of Korea

${ }^{e}$ Department of Chemical and Biomolecular Engineering, Yonsei University, Seoul 03722, Republic of Korea. E-mail:jhcho94@yonsei.ac.kr

$\dagger$ Electronic supplementary information (ESI) available. See DOI: 10.1039/c8ra09831j considerably and have already reached a level comparable to or even higher than the performance levels of amorphous $\mathrm{Si}$ transistors. ${ }^{4,8-10}$ In addition to the development of semiconductors with high carrier mobilities and electrodes with high conductivities, the development of gate dielectric materials is crucial for the fabrication of high-performance OFET devices. Thus far, high-performance OFETs have been achieved using inorganic gate dielectrics such as $\mathrm{SiO}_{2}, \mathrm{Al}_{2} \mathrm{O}_{3}$, and $\mathrm{HfO}_{2} \cdot{ }^{11-13}$ However, they are usually prepared by complex, expensive vacuum processes such as physical vapor deposition, ${ }^{\mathbf{1 4}, 15}$ chemical vapor deposition, ${ }^{\mathbf{1 6}, \mathbf{1 7}}$ and atomic layer deposition. ${ }^{18,19}$

$\mathrm{SiO}_{2}$ is one of the most important insulating materials for application as a gate dielectric or encapsulation layer in various electronic devices. Several research groups have fabricated the $\mathrm{SiO}_{2}$ layer by conversion of spin-on-glass (SOG) materials such as perhydropolysilazane (PHPS), silsesquioxane, tetraethyl orthosilicate, and tetramethyl orthosilicate. ${ }^{\mathbf{2 0 - 2 4}}$ Because of the low cost, simplicity, and excellent substrate adaptability of this approach, this process can replace the conventional vapor deposition process. PHPS, used in this study, is one of the most widely used SOG materials because of its low carbon contamination and ability to form dense films. ${ }^{25-28}$ Among the various methods for the conversion of PHPS to $\mathrm{SiO}_{2}$, a commonly utilized one is thermal 
annealing. ${ }^{27,29}$ However, this process requires high temperatures above $500{ }^{\circ} \mathrm{C}$, which limits the applicability of PHPS on polymer substrates with low glass transition temperatures. To overcome this problem, various types of low-temperature conversion methods using catalysts have been developed. For instance, gaseous ammonia ${ }^{30}$ or hydrogen peroxide ${ }^{31,32}$ can promote the conversion of PHPS to $\mathrm{SiO}_{2} \cdot{ }^{32}$ However, achieving complete conversion of PHPS to $\mathrm{SiO}_{2}$ remains difficult. Furthermore, significant contamination by catalysts may result in a fatal defect in the film and degradation of the gate dielectric properties.

In this study, conversion of PHPS was performed using intense pulsed UV light (IPL), which is a rapid and efficient conversion method at room temperature. The conversion of PHPS to $\mathrm{SiO}_{2}$ by IPL irradiation is a more effective approach for the synthesis of a dense silica film than the previous method of using vacuum UV, which requires complicated equipment such as a vacuum chamber. ${ }^{33,34}$ Moreover, the former approach is more efficient than the latter one in a similar spectral range because PHPS is exposed to photon energies higher than its structural binding energy ( $\left.92 \mathrm{kcal} \mathrm{mol}^{-1}\right) .{ }^{35}$ In this study, the $\mathrm{SiO}_{2}$ layer obtained by IPL irradiation of PHPS was utilized as a gate dielectric layer in high-performance OFETs and complementary inverters. The conversion of the spin-coated PHPS film was systematically controlled by varying both the number of intense pulses and the applied voltage. The structural properties and gate dielectric properties of the PHPSderived $\mathrm{SiO}_{2}$ films were systematically investigated by Fourier transform infrared (FT-IR) spectroscopy and leakage current measurements, respectively. In addition, a complementary inverter - which is a fundamental component of logic circuits-was constructed by integrating a p-type pentacene OFET and an n-type PTCDI-C 8 OFET with the $\mathrm{SiO}_{2}$ gate dielectric derived from IPL-converted PHPS.

\section{Results and discussion}

Fig. 1a shows a schematic image of OFETs including a $\mathrm{SiO}_{2}$ gate dielectric layer derived from PHPS by IPL irradiation. A heavily doped Si wafer was used as a gate electrode. Commercial PHPS (18 wt\% in xylene; DNF Co., Korea) was deposited by the spincoating method onto the Si wafer to a thickness of around $524 \mathrm{~nm}$. As is clear from the chemical structure in Fig. 1a, PHPS (number-average molecular weight $\left(M_{\mathrm{n}}\right): 2000 \mathrm{~g} \mathrm{~mol}^{-1}$, weightaverage molecular weight $\left(M_{\mathrm{w}}\right): 10000 \mathrm{~g} \mathrm{~mol}^{-1}$, and polydispersity index (PDI): 2.3) is an inorganic polymer with a $\mathrm{Si}-\mathrm{N}$ skeleton and $\mathrm{Si}-\mathrm{H}$ side groups. ${ }^{28,36}$ In this study, PHPS was converted to $\mathrm{SiO}_{2}$ by IPL irradiation and its gate dielectric properties were compared with those of thermally derived $\mathrm{SiO}_{2}$ (from the same PHPS) and commercial thermally grown $\mathrm{SiO}_{2}$. Onto the PHPS-derived $\mathrm{SiO}_{2}$ gate dielectric layer was deposited a p-type pentacene film or an n-type PTCDI- $\mathrm{C}_{8}$ film by the thermal evaporation method. Finally, $\mathrm{Au}$ source and drain electrodes were patterned through the thermal evaporation method. The channel length $(L)$ and width $(W)$ were 100 and $1000 \mu \mathrm{m}$, respectively.

Fig. 1b shows the curing mechanism of PHPS. PHPS can be converted to $\mathrm{SiO}_{2}$ through two different mechanisms: (i) hydrolysis and polycondensation in the presence of water ${ }^{28}$ and (ii) a photolytic process in the presence of oxygen. ${ }^{33}$ In the presence of water molecules under humid conditions, oxidation occurs by the hydrolysis of both the $\mathrm{Si}-\mathrm{N}$ and the $\mathrm{Si}-\mathrm{H}$ bonds, which leads to a release of gaseous ammonia and hydrogen and the formation of silanol groups. In the subsequent thermal condensation process, the silanol groups are transformed into $\mathrm{SiO}_{2}$ by the elimination of $\mathrm{H}_{2} \mathrm{O}$. However, thermal treatment has some drawbacks in that high processing temperatures above $500{ }^{\circ} \mathrm{C}$ and long processing times-longer than $5 \mathrm{~h}$-are required for complete conversion of PHPS to $\mathrm{SiO}_{2}$ without the formation
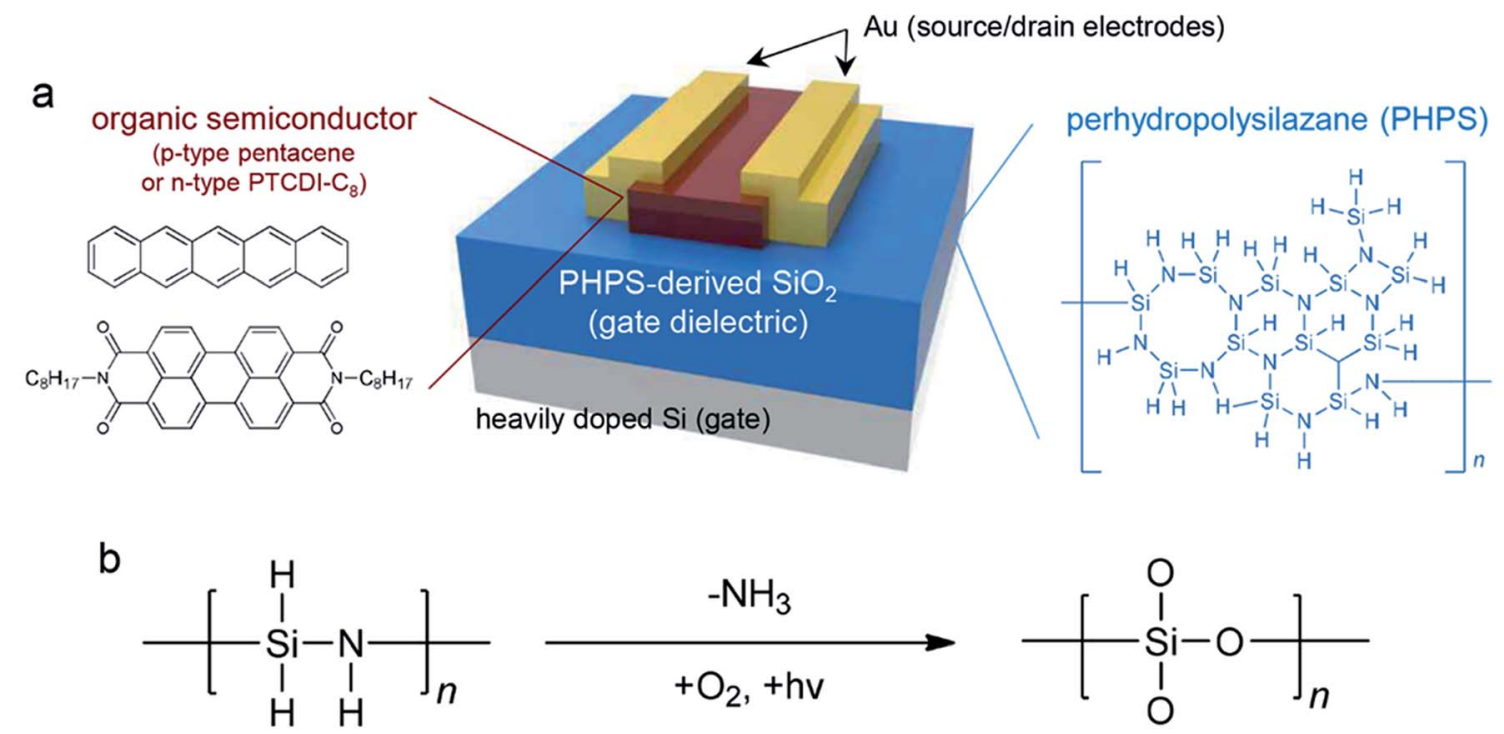

Fig. 1 (a) Schematic structure of OFETs based on $\mathrm{SiO}_{2}$ gate dielectric layer derived from PHPS by IPL. The left panel shows the chemical structures of pentacene and PTCDI- $\mathrm{C}_{8}$, and the right panel shows the chemical structure of PHPS. (b) Curing mechanism of PHPS. 
of intermediates such as silanol groups. This process is similar to the typical sol-gel reaction. In the case of the photolytic process, high-energy UV irradiation causes dissociation of chemical bonds and generation of ozone molecules $\left(\mathrm{O}_{3}\right)$ and oxygen radicals (O, one-dimensional). This results in the direct substitution of a Si atom with activated oxygen and, finally, the formation of $\mathrm{SiO}_{x}$. IPL irradiation induces a nuclear reaction by accelerating charged particles with kinetic energy, which is stronger than the irradiation by an ordinary UV lamp. IPL irradiation uses a photon energy of 4.43-12.4 eV with a wavelength range of 100-280 $\mathrm{nm}$, which corresponds to the UV-C range in the electromagnetic spectrum. The high-energy UV photons promote the dissociation of the $\mathrm{Si}-\mathrm{N}$ bond and the formation of $\mathrm{Si}$ free radicals and consequently form $\mathrm{SiO}_{x}$ through oxidation with activated oxygen. The IPL irradiation method drastically reduces the conversion time $(<2 \mathrm{~h})$, which consequently results in an improvement in the productivity compared to the thermal annealing method, which requires high temperatures $\left(>500{ }^{\circ} \mathrm{C}\right)$ and long processing times $(>5 \mathrm{~h})$. Furthermore, this room-temperature process enables the deposition of materials on plastic substrates with low glass transition temperatures.

The chemical structure of the PHPS-derived $\mathrm{SiO}_{2}$ films was investigated by FT-IR spectroscopy. Fig. 2 shows the FT-IR absorption spectra of the PHPS-derived $\mathrm{SiO}_{2}$ films and their gate dielectric properties. The as-coated PHPS film showed three characteristic absorption bands, which were attributed to the $\mathrm{N}-\mathrm{H}, \mathrm{Si}-\mathrm{H}$, and $\mathrm{Si}-\mathrm{N}$ bonds. ${ }^{28,36-38}$ In the spectrum, the absorption bands positioned at 1178 and $3372 \mathrm{~cm}^{-1}$ corresponded to the bending and stretching modes of the $\mathrm{N}-\mathrm{H}$ bond, respectively. The absorption peak at $2165 \mathrm{~cm}^{-1}$ corresponded to the stretching vibration of the $\mathrm{Si}-\mathrm{H}$ bond, and the absorption peaks at 920 and $840 \mathrm{~cm}^{-1}$ were attributed to the stretching vibrations of $\mathrm{Si}-\mathrm{N}$ in the $\mathrm{Si}-\mathrm{N}-\mathrm{Si}$ bond. The curing condition of PHPS was systematically optimized by varying both the number of intense pulses and the applied voltage, as shown in Fig. 2a and b. Specifically, Fig. 2a shows the FT-IR spectra of the PHPS films prepared at various applied voltages. The number of intense pulses was fixed at 6000 counts. With an increase in the applied voltage of the IPL irradiation, the $\mathrm{Si}-\mathrm{N}, \mathrm{Si}-\mathrm{H}$, and $\mathrm{N}-\mathrm{H}$ absorption bands decreased gradually and disappeared completely at $3.0 \mathrm{kV}$. Simultaneously, absorption peaks at 800 and $1170 \mathrm{~cm}^{-1}$, attributed to the stretching vibrations of the $\mathrm{Si}-$ $\mathrm{O}$ and $\mathrm{Si}-\mathrm{O}-\mathrm{Si}$ bonds appeared, respectively. ${ }^{36,39,40}$ In addition, a new absorption peak at $3670 \mathrm{~cm}^{-1}$ corresponding to the $\mathrm{Si}-$ $\mathrm{OH}$ bond-appeared at $3.0 \mathrm{kV}$, which was related to the undesirable dangling bonds formed during the conversion process. ${ }^{41}$ It could be concluded that the $\mathrm{SiO}_{2}$ network was formed by the hydrolysis of the Si-NH bonds and the subsequent formation of the $\mathrm{Si}-\mathrm{O}$ bond. Subsequently, the number of intense pulses was increased to 8000 counts while maintaining the applied voltage at $3.0 \mathrm{kV}$. With an increase in the number of intense pulses, the stretching vibration of the $\mathrm{Si}-\mathrm{H}$ bond at $2165 \mathrm{~cm}^{-1}$ decreased gradually, as shown in Fig. 2b. Although the absorption peak of the $\mathrm{Si}-\mathrm{OH}$ bond disappeared completely at 8000 counts, microcracks were formed on the PHPS-derived $\mathrm{SiO}_{2}$ film (Fig. S1 $\dagger$ ) and the leakage current increased significantly
(Fig. S2 $\dagger$ ). The FT-IR spectrum of the $\mathrm{SiO}_{2}$ film derived from IPLconverted PHPS was compared with that of a $\mathrm{SiO}_{2}$ film derived from PHPS by thermal treatment at $600{ }^{\circ} \mathrm{C}$ for $5 \mathrm{~h}$, as shown in Fig. 2c. Both these FT-IR spectra were similar to each other in terms of the shape of the absorption peaks achieved by the different conversion methods. It is noteworthy that the PHPS films could be converted to $\mathrm{SiO}_{2}$ by IPL irradiation at room temperature, similar to what could be achieved via thermal treatment. However, it was considered that the electrical properties of the PHPS-derived $\mathrm{SiO}_{2}$ film would be affected by its subtle $\mathrm{SiO}_{2}$ lattice structure. Therefore, the PHPS-derived $\mathrm{SiO}_{2}$ films were prepared for use as a gate dielectric layer in OFETs under the optimized condition of $3.0 \mathrm{kV}$ and 6000 counts achieved via systematic variation of the irradiation conditions.

The leakage current densities of the $\mathrm{SiO}_{2}$ gate dielectric derived from IPL-converted PHPS were measured using the metal-insulator-metal (MIM) geometry, as shown in Fig. 2d. The PHPS film converted at $1 \mathrm{kV}$ showed a huge leakage current even under an electric field lower than $0.1 \mathrm{MV} \mathrm{cm}^{-1}$. With an increase in the applied voltage during the IPL irradiation to 2.5 $\mathrm{kV}$, the leakage current reduced gradually and then saturated above $2.5 \mathrm{kV}$. For example, the PHPS-derived $\mathrm{SiO}_{2}$ film converted at $1.5 \mathrm{kV}$ showed a leakage current density of $7.9 \times 10^{-11}$ A cm${ }^{-2}$ at $1.5 \mathrm{MV} \mathrm{cm}^{-1}$ and that converted at $2.5 \mathrm{kV}$ showed a leakage current density that was more than one order of magnitude lower, $3.0 \times 10^{-12} \mathrm{~A} \mathrm{~cm}^{-2}$, at $1.5 \mathrm{MV} \mathrm{cm}^{-1}$. Fig. $2 \mathrm{e}$ shows the leakage current density of the PHPS-derived $\mathrm{SiO}_{2}$ film at $1.5 \mathrm{MV} \mathrm{cm}^{-1}$ as a function of the applied voltage. A further increase in the voltage to up to $3.0 \mathrm{kV}$ improved the electrical stability at high electric fields above $2 \mathrm{MV} \mathrm{cm}^{-1}$. This leakage current level was superior compared with those of typical polymer gate dielectrics such as poly(methyl methacrylate), polystyrene, and fluorinated polymers. ${ }^{42-46}$ As a result, the PHPS-derived $\mathrm{SiO}_{2}$ film at $3.0 \mathrm{kV}$ and 6000 counts were chosen as a gate dielectric layer for fabricating the OFETs. Fig. $2 \mathrm{f}$ shows the specific capacitance of the optimized PHPS-derived $\mathrm{SiO}_{2}$ film as a function of frequency. The film thickness was around $525 \mathrm{~nm}$ (Fig. S3†). The capacitance value was measured to be $3.48 \mathrm{nF} \mathrm{cm} \mathrm{cm}^{-2}$ at $100 \mathrm{~Hz}$, and it showed a weak dependence on frequency. The dielectric constant $(k)$ calculated from the capacitance and thickness was around 3.8 at $1 \mathrm{MHz}$, which was identical to that of a thermally grown $\mathrm{SiO}_{2}$ layer $(k \sim 3.9)$. It should be noted that PHPS was fully converted to $\mathrm{SiO}_{2}$ by the IPL irradiation at room temperature and that this film exhibited high electrical stability.

Fig. 3 shows the device performance of OFETs with the $\mathrm{SiO}_{2}$ gate dielectric derived from IPL-converted PHPS. The electrical properties of these OFETs were compared with those of an OFET with the $\mathrm{SiO}_{2}$ gate dielectric thermally derived from PHPS and an OFET with the thermally grown $\mathrm{SiO}_{2}$ gate dielectric. Fig. 3a shows the output characteristics (drain current $\left(I_{\mathrm{D}}\right)$ versus drain voltage $\left(V_{\mathrm{D}}\right)$ ) of the pentacene OFET with the $\mathrm{SiO}_{2}$ gate dielectric derived from IPL-converted PHPS at various gate voltages $\left(V_{\mathrm{G}}\right)$. The curves showed the gate modulation of $I_{\mathrm{D}}$ in both the linear regime and the saturation regime. The left panel of Fig. $3 \mathrm{~b}$ shows the transfer characteristics $\left(I_{\mathrm{D}}-V_{\mathrm{G}}\right)$ of the pentacene OFET with the $\mathrm{SiO}_{2}$ gate dielectric derived from IPL-converted 

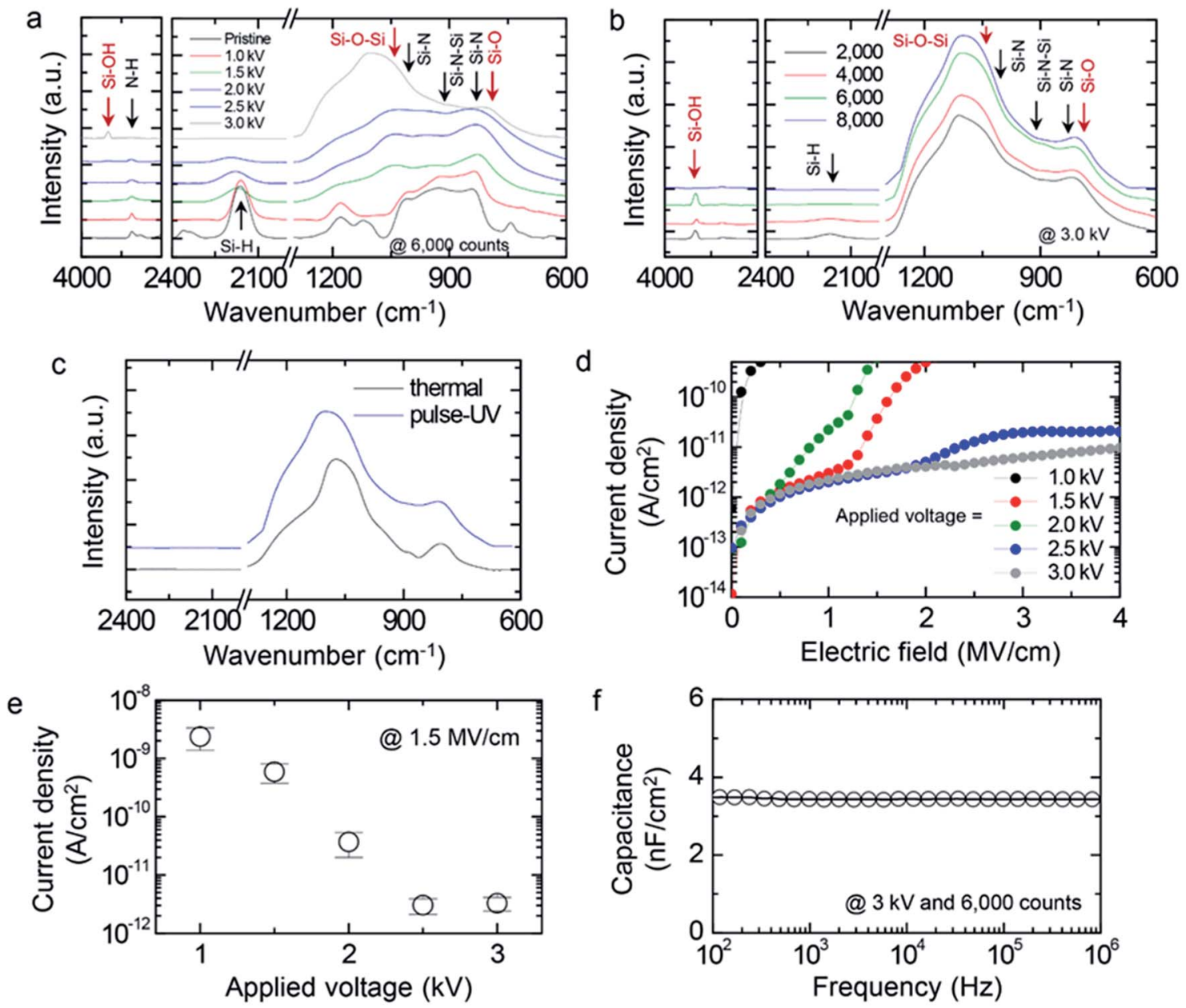

Fig. 2 (a) FT-IR spectra of PHPS films prepared at various applied voltages during IPL irradiation. The number of counts was fixed at 6000. (b) FTIR spectra of PHPS films prepared at various numbers of intense pulses of IPL. The applied voltage was fixed at $3.0 \mathrm{kV}$. (c) $\mathrm{FT}$-IR spectra of $\mathrm{SiO}$, film derived from PHPS by IPL irradiation ( $3.0 \mathrm{kV}$ and 6000 counts) and that derived from PHPS by thermal treatment ( $600{ }^{\circ} \mathrm{C}$ and $5 \mathrm{~h}$ ). (d) $\mathrm{Current}$ density of PHPS films prepared at various applied voltages during IPL irradiation as a function of electric field. (e) Current density of PHPS films prepared at various applied voltages during IPL irradiation at $1.5 \mathrm{MV} \mathrm{cm}^{-1}$. (f) Specific capacitance of $\mathrm{SiO}_{2}$ film derived from PHPS by IPL irradiation (3.0 kV and 6000 counts).

PHPS at $V_{\mathrm{D}}=-40 \mathrm{~V}$. The pentacene device turned on sharply near $0 \mathrm{~V}$ and its $I_{\mathrm{D}}$ increased with a decrease in $V_{\mathrm{G}}$ in the negative direction, which is a characteristic feature of p-type operation of a transistor. The carrier mobility $(\mu)$ in the saturation regime was evaluated according to the formula $I_{\mathrm{D}}=C_{\mathrm{S}^{-}}$ $\mu W\left(V_{\mathrm{G}}-V_{\mathrm{TH}}\right)^{2} /(2 L)$, where $L$ and $W$ are the length and width, respectively, of the device channel; $C_{\mathrm{S}}$ is the specific capacitance of the gate dielectric (3.48 $\mathrm{nF} \mathrm{cm}^{-2}$ for IPL-converted PHPS), and $V_{\mathrm{TH}}$ is the threshold voltage. ${ }^{47,48}$ The $\mu$ value of the pentacene OFET with the $\mathrm{SiO}_{2}$ gate dielectric derived from IPLconverted PHPS was $0.16( \pm 0.01) \mathrm{cm}^{2} \mathrm{~V}^{-1} \mathrm{~s}^{-1}$. It should be noted that this value was comparable to those of the OFETs with the $\mathrm{SiO}_{2}$ gate dielectric thermally derived from PHPS (0.14 $\left.( \pm 0.01) \mathrm{cm}^{2} \mathrm{~V}^{-1} \mathrm{~s}^{-1}\right)$ and the thermally grown $\mathrm{SiO}_{2}$ gate dielectric $\left(0.15( \pm 0.01) \mathrm{cm}^{2} \mathrm{~V}^{-1} \mathrm{~s}^{-1}\right)$ (see Fig. $\left.\mathrm{S} 4 \dagger\right)$. The on-off current ratio was around $10^{6}$ and $V_{\mathrm{TH}}$ was around $-50 \mathrm{~V}$. The device parameters, including $\mu$, the on-off current ratio, and $V_{\mathrm{TH}}$, are summarized in Fig. $3 \mathrm{c}$.
Additionally, PTCDI- $\mathrm{C}_{8}$ was utilized as the n-type semiconductor counterpart to pentacene utilized as the p-type semiconductor. The right panel of Fig. 3b shows the transfer characteristics of the PTCDI-C 8 OFET with the $\mathrm{SiO}_{2}$ gate dielectric derived from IPL-converted PHPS at $V_{\mathrm{D}}=+40 \mathrm{~V}$. In contrast to $I_{\mathrm{D}}$ of the pentacene OFET, that of the PTCDI-C $\mathrm{C}_{8}$ OFET increased with an increase in $V_{\mathrm{G}}$ in the positive direction, which is a direct signature of the n-type operation of a transistor (also see Fig. S5 $\dagger$ ). The PTCDI-C 8 OFET with the $\mathrm{SiO}_{2}$ gate dielectric derived from IPL-converted PHPS showed electron mobility of $0.02( \pm 0.01) \mathrm{cm}^{2} \mathrm{~V}^{-1} \mathrm{~s}^{-1}$. The lower carrier mobility of the $\mathrm{n}$ type OFET than of the p-type OFET may be attributed to the fact that electrons were easily trapped at the charge-trap sites formed at the interface between the semiconductor layer and the gate dielectric layer. However, this value was comparable to those of the OFETs with the $\mathrm{SiO}_{2}$ gate dielectric thermally derived from PHPS $\left(0.01( \pm 0.018) \mathrm{cm}^{2} \mathrm{~V}^{-1} \mathrm{~s}^{-1}\right)$ and the thermally grown $\mathrm{SiO}_{2}$ gate dielectric $\left(0.02( \pm 0.002) \mathrm{cm}^{2} \mathrm{~V}^{-1} \mathrm{~s}^{-1}\right)$. 

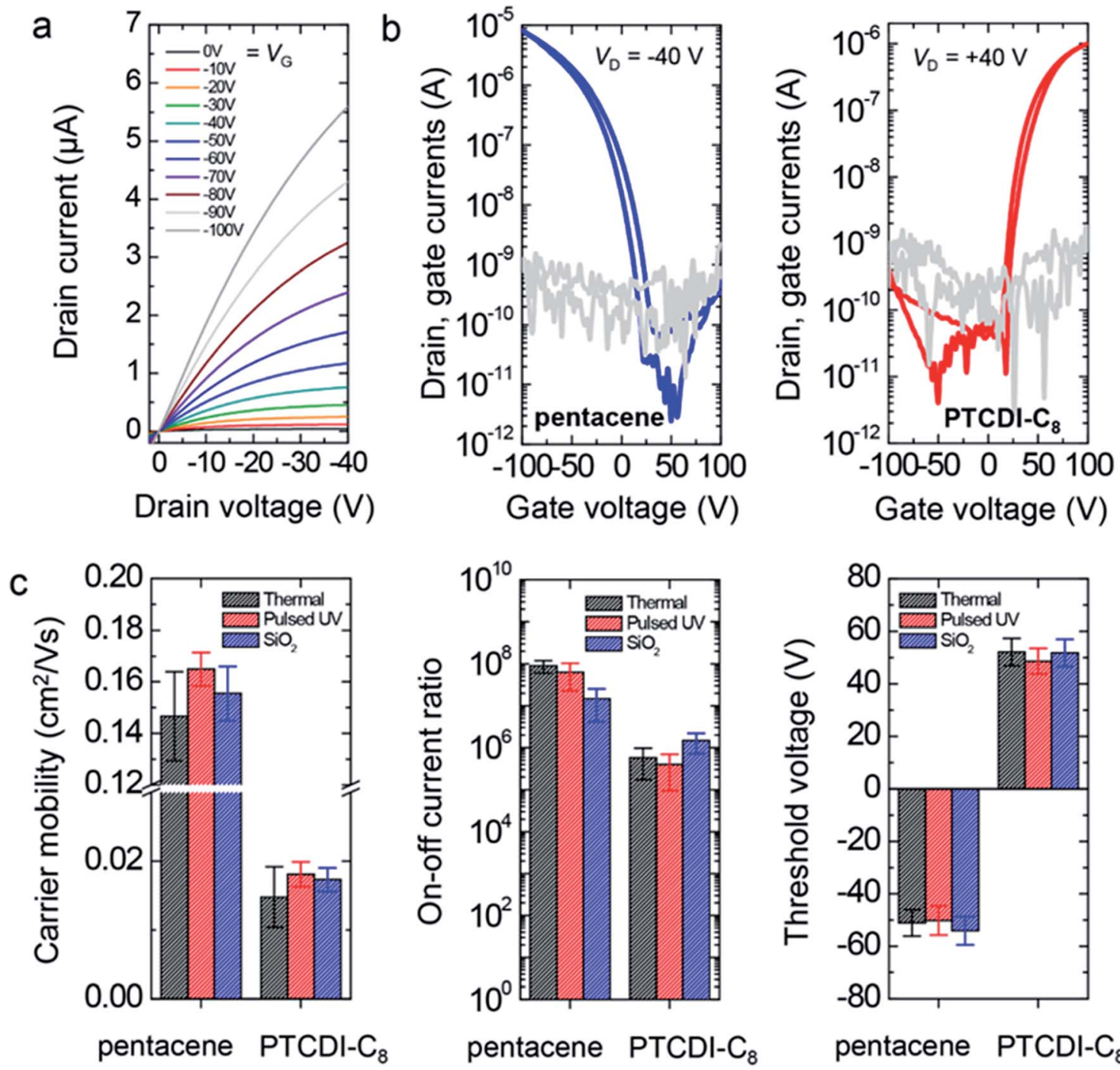

Fig. 3 (a) Output characteristics of p-type pentacene OFET with $\mathrm{SiO}_{2}$ film derived from PHPS by IPL irradiation (3.0 kV and 6000 counts). (b) Transfer characteristics of $\mathrm{p}$-type pentacene (left) and n-type PTCDI- $\mathrm{C}_{8}$ (right) OFETs with $\mathrm{SiO}_{2}$ film derived from PHPS by IPL irradiation (3.0 kV and 6000 counts). (c) Carrier mobility, on-off current ratio, and threshold voltage of OFETs with $\mathrm{SiO}_{2}$ film derived from PHPS by IPL irradiation (3.0 kV and 6000 counts), $\mathrm{SiO}_{2}$ film derived from PHPS by thermal treatment $\left(600^{\circ} \mathrm{C}\right.$ and $5 \mathrm{~h}$ ), and commercial thermally grown $\mathrm{SiO}_{2}$ film.

The device showed an on-off current ratio of around $10^{5}$ and $V_{\mathrm{TH}}$ of around $+50 \mathrm{~V}$. A slight hysteresis between the forward and reverse sweeps was observed in both OFETs because of the generation of charge traps from the $\mathrm{Si}-\mathrm{OH}$ groups formed during the conversion process (see Fig. 2a). The gate leakage currents of both the p-type and the n-type OFETs were also monitored during measurement of the transfer curves. It is noteworthy that both these devices showed a gate leakage current of around $10^{-10} \mathrm{~A}$, which was comparable to that of the device with the $\mathrm{SiO}_{2}$ gate dielectric thermally derived from PHPS.

Finally, a complementary inverter, which is the most basic component of logic circuits, was constructed by integrating a p-type pentacene OFET and an n-type PTCDI-C ${ }_{8}$ OFET with the $\mathrm{SiO}_{2}$ gate dielectric derived from IPL-converted PHPS (Fig. 4a). The p-type OFET was connected to the supply electrode, whereas the n-type OFET was connected to the ground. Both these OFETs shared the same input and output terminals. Fig. 4b shows the corresponding circuit diagram. Fig. 4c shows the voltage transfer characteristics of the constructed complementary inverter at four different $V_{\mathrm{DD}}$ values. The device exhibited ideal rail-to-rail output swing. When a low input voltage $\left(V_{\text {IN }}\right)$ was applied, the p-type OFET turned on but the n-type OFET turned off. Thus, the output voltage ( $\left.V_{\text {OUT }}\right)$ was the same as the applied $V_{\text {DD }}(10,20,30$, or $40 \mathrm{~V})$. As $V_{\text {IN }}$ increased, the p- and n-type OFETs turned off and on, respectively. $V_{\text {OUT }}$ approached $0 \mathrm{~V}$. Fig. $4 \mathrm{~d}$ shows the static gain-which refers to the absolute value of $\mathrm{d} V_{\text {OUT }} / \mathrm{d} V_{\text {IN }}-$ of the inverter as a function of $V_{\mathrm{IN}}$. The device showed a maximum inverter gain of 1.8 at $V_{\mathrm{DD}}=40 \mathrm{~V}$. 
a
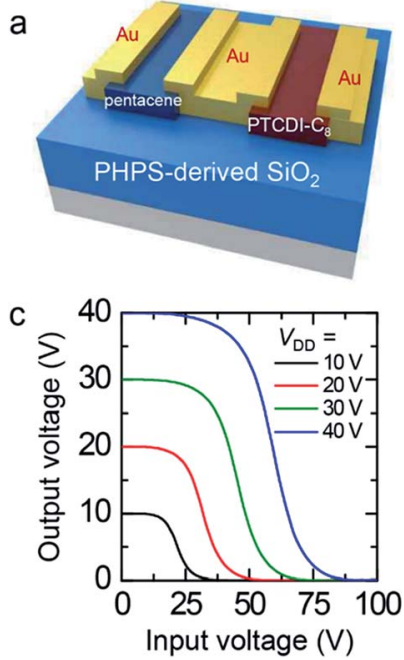
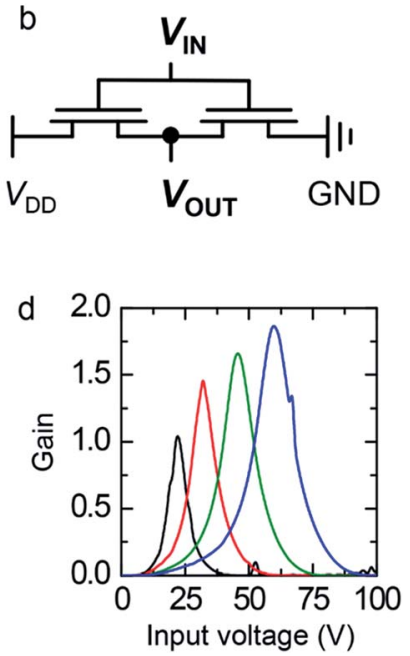

Fig. 4 (a) Schematic illustration and (b) circuit diagram of complementary inverter with $\mathrm{SiO}_{2}$ gate dielectric derived from PHPS by IPL irradiation (3.0 kV and 6000 counts). (c) Voltage transfer characteristics and (d) signal gain of complementary inverter.

\section{Conclusion}

We fabricated OFETs and a complementary inverter including $\mathrm{a} \mathrm{SiO}_{2}$ gate dielectric layer derived from PHPS by IPL irradiation. The spin-coated PHPS was completely converted to $\mathrm{SiO}_{2}$ by optimizing both the number of intense pulses and the applied voltage. PHPS-derived $\mathrm{SiO}_{2}$ films at $3.0 \mathrm{kV}$ and 6000 counts were utilized as a gate dielectric layer in p-type pentacene and n-type PTCDI-C ${ }_{8}$ OFETs. The gate dielectric properties of the PHPSderived $\mathrm{SiO}_{2}$ films were systematically investigated. The resulting $\mathrm{SiO}_{2}$ films were successfully applied as a gate dielectric layer in p-type pentacene and n-type PTCDI- $\mathrm{C}_{8}$ OFETs. The resulting OFETs showed good electrical properties, such as carrier mobilities of $0.16( \pm 0.01) \mathrm{cm}^{2} \mathrm{~V}^{-1} \mathrm{~s}^{-1}$ (for the pentacene OFET) and $0.02( \pm 0.01) \mathrm{cm}^{2} \mathrm{~V}^{-1} \mathrm{~s}^{-1}$ (for the PTCDI-C ${ }_{8}$ OFET) and an on-off current ratio larger than $10^{5}$, which were comparable to those of OFETs with commercial thermally grown $\mathrm{SiO}_{2}$ and $\mathrm{SiO}_{2}$ thermally derived from PHPS. The use of IPL to convert PHPS to $\mathrm{SiO}_{2}$ for use as a gate dielectric layer in OFETs is expected to serve as a novel approach for the fabrication of large-area flexible electronics in the flexible device industry of the future.

\section{Experimental}

\section{Device fabrication}

A Si wafer was used as the substrate. The substrate was cleaned in an ultrasonic bath sequentially with acetone, isopropanol, and deionized water for $10 \mathrm{~min}$ each. An $18 \mathrm{wt} \%$ PHPS solution (DNF Co., Ltd., Korea) in xylene was spin-coated onto the substrate at $5000 \mathrm{rpm}$ for $30 \mathrm{~s}$. The PHPS film was prebaked on a hotplate at $150{ }^{\circ} \mathrm{C}$ for $10 \mathrm{~min}$ to remove residual solvent. The resulting film was converted to $\mathrm{SiO}_{2}$ by using IPL (X-1000, xenon) at room temperature. The distance between light source and sample was $2.5 \mathrm{~cm}$. A pulse width of $500 \mu \mathrm{s}$ and

pulse interval of $0.64 \mathrm{~Hz}$ were used in the air atmosphere. Both the number of intense pulses and the applied voltage were varied. The thickness of the PHPS-derived $\mathrm{SiO}_{2}$ film was around $524 \mathrm{~nm}$. Pentacene and PTCDI- $\mathrm{C}_{8}$ films, each $40 \mathrm{~nm}$ in thickness, were deposited onto the gate dielectric at a rate of $0.1 \mathrm{~A} \mathrm{~s}^{-1}$ by using a thermal evaporator. Finally, Au source and drain electrodes were thermally deposited through a shadow mask. The channel length $(L)$ and width $(W)$ were 100 and $1000 \mu \mathrm{m}$, respectively.

\section{Characterization}

Fourier transform infrared (FT-IR) spectra of samples were recorded on a Nicolet 6700 FT-IR Spectrometer from ThermoElectron. Specific capacitances of gate dielectrics were measured with Agilent E-4980A LCR meter. Electrical properties of transistors were measured using Keithley 4200 semiconductor characterization system.

\section{Conflicts of interest}

There are no conflicts to declare.

\section{Acknowledgements}

This work was supported by the Ministry of Trade, Industry \& Energy, Korea Institute for Advancement of Technology through the Encouragement Program for The Industries of Economic Cooperation Region (17-107-002, R0006234), the Center for Advanced Soft Electronics (CASE) under the Global Frontier Research Program (2013M3A6A5073177), and the Basic Science Research Program through the National Research Foundation of Korea (NRF) funded by the Ministry of Education (2017R1A2B2005790), Republic of Korea.

\section{References}

1 S. Reineke, F. Lindner, G. Schwartz, N. Seidler, K. Walzer, B. Lüssem and K. Leo, Nature, 2009, 459, 234-238.

2 J. Wu, H. A. Becerril, Z. Bao, Z. Liu, Y. Chen and P. Peumans, Appl. Phys. Lett., 2008, 92, 263302.

3 G. Horowitz, Adv. Mater., 1999, 10, 365-377.

4 M. J. Kim, A.-R. Jung, M. Lee, D. Kim, S. Ro, S.-M. Jin, H. D. Nguyen, J. Yang, K.-K. Lee, E. Lee, M. S. Kang, H. Kim, J.-H. Choi, B. Kim and J. H. Cho, ACS Appl. Mater. Interfaces, 2017, 9, 40503-40515.

5 C. B. Park, K. M. Kim, J. E. Lee, H. Na, S. S. Yoo and M. S. Yang, Org. Electron., 2014, 15, 3538-3545.

6 R. Rotzoll, S. Mohapatra, V. Olariu, R. Wenz, M. Grigas, K. Dimmler, O. Shchekin and A. Dodabalapur, Appl. Phys. Lett., 2006, 88, 123502.

7 V. Subramanian, P. C. Chang, J. B. Lee, S. E. Molesa and S. K. Volkman, IEEE Trans. Compon. Packag. Technol., 2005, 28, 742-747.

8 P. S. K. Amegadze and Y.-Y. Noh, J. Inf. Disp., 2014, 15, $213-$ 229. 
9 M. Lee, M. J. Kim, S. Ro, S. Choi, S.-M. Jin, H. D. Nguyen, J. Yang, K.-K. Lee, D. U. Lim, E. Lee, M. S. Kang, J.-H. Choi, J. H. Cho and B. Kim, ACS Appl. Mater. Interfaces, 2017, 9, 28817-28827.

10 N.-K. Kim, S.-Y. Jang, G. Pace, M. Caironi, W.-T. Park, D. Khim, J. Kim, D.-Y. Kim and Y.-Y. Noh, Chem. Mater., 2015, 27, 8345-8353.

11 X.-H. Zhang, B. Domercq, X. Wang, S. Yoo, T. Kondo, Z. L. Wang and B. Kippelen, Org. Electron., 2007, 8, 718-726.

12 Y. Su, C. Wang, W. Xie, F. Xie, J. Chen, N. Zhao and J. Xu, ACS Appl. Mater. Interfaces, 2011, 3, 4662-4667.

13 S. Ono, R. Häusermann, D. Chiba, K. Shimamura, T. Ono and B. Batlogg, Appl. Phys. Lett., 2014, 104, 013307.

14 H. Watanabe, M. Saitoh, N. Ikarashi and T. Tatsumi, Appl. Phys. Lett., 2004, 85, 449-451.

15 F. Iacopi, Z. Tőkei, Q. T. Le, D. Shamiryan, T. Conard, B. Brijs, U. Kreissig, M. Van Hove and K. Maex, J. Appl. Phys., 2002, 92, 1548-1554.

16 C. M. Perkins, B. B. Triplett, P. C. McIntyre, K. C. Saraswat, S. Haukka and M. Tuominen, Appl. Phys. Lett., 2001, 78, 2357-2359.

17 A.-D. Li, Q.-Y. Shao, H.-Q. Ling, J.-B. Cheng, D. Wu, Z.-G. Liu, N.-B. Ming, C. Wang, H.-W. Zhou and B.-Y. Nguyen, Appl. Phys. Lett., 2003, 83, 3540-3542.

18 M. M. Frank, G. D. Wilk, D. Starodub, T. Gustafsson, E. Garfunkel, Y. J. Chabal, J. Grazul and D. A. Muller, Appl. Phys. Lett., 2005, 86, 152904.

19 E. P. Gusev, C. Cabral, M. Copel, C. D'Emic and M. Gribelyuk, Microelectron. Eng., 2003, 69, 145-151.

20 M. D. Cheng, T. Luoh, C. T. Su, T. H. Yang, K. C. Chen and C. Y. Lu, Thin Solid Films, 2008, 516, 8726-8730.

21 D. Hishitani, M. Horita, Y. Ishikawa, H. Ikenoue and Y. Uraoka, Jpn. J. Appl. Phys., 2017, 56, 056503.

22 W. Kang, G. An, M. J. Kim, W. H. Lee, D. Y. Lee, H. Kim and J. H. Cho, J. Phys. Chem. C, 2016, 120, 3501-3508.

23 M. J. Kim, Y. M. Heo and J. H. Cho, Org. Electron., 2017, 43, 41-46.

24 R. Usuda, K. Uchida and S. Nozaki, Appl. Phys. Lett., 2015, 107, 182903.

25 H. Kozuka, K. Nakajima and H. Uchiyama, ACS Appl. Mater. Interfaces, 2013, 5, 8329-8336.

26 J. Song, D. Wang, L. Hu, X. Huang and Y. Chen, Appl. Surf. Sci., 2018, 455, 771-779.

27 K. Kamiya, T. Tange and T. Hashimoto, Res. Rep. Fac. Eng., Mie Univ., 2001, 26, 23-31.

28 A. Morlier, S. Cros, J.-P. Garandet and N. Alberola, Thin Solid Films, 2012, 524, 62-66.
29 K. Kamiya, A. Oka, H. Nasu and T. Hashimoto, J. Sol-Gel Sci. Technol., 2000, 19, 495-499.

30 T. Kubo and H. Kozuka, J. Ceram. Soc. Jpn., 2006, 114, 517523.

31 T. Tanaka, K. Hanaoka, M. Yamaguchi, T. Shindo, K.-H. Kunzelmann and T. Teranaka, Dent. Mater., 2011, 30, 170-175.

32 J.-S. Lee, J.-H. Oh, S.-W. Moon, W.-S. Sul and S.-D. Kim, Electrochem. Solid-State Lett., 2010, 13, H23-H25.

33 L. Prager, A. Dierdorf, H. Liebe, S. Naumov, S. Stojanović, R. Heller, L. Wennrich and M. R. Buchmeiser, Chem.-Eur. J., 2007, 13, 8522-8529.

34 Y. Naganuma, S. Tanaka, C. Kato and T. Shindo, J. Ceram. Soc. Jpn., 2004, 112, 599-603.

35 T. Ohishi, Y. Yamazaki and T. Nabatame, Frontiers in Nanoscience and Nanotechnology, 2016, 2, 149-154.

36 Z. Zhang, Z. Shao, Y. Luo, P. An, M. Zhang and C. Xu, Polym. Int., 2015, 64, 971-978.

37 K. Wang, M. Günthner, G. n. Motz, B. D. Flinn and R. K. Bordia, Langmuir, 2013, 29, 2889-2896.

38 K. Wang, X. Zheng, F. S. Ohuchi and R. K. Bordia, J. Am. Ceram. Soc., 2012, 95, 3722-3725.

39 K. Nakajima, H. Uchiyama, T. Kitano and H. Kozuka, J. Am. Ceram. Soc., 2013, 96, 2806-2816.

40 H. S. Lee, K. Park, J.-D. Kim, T. Han, K. H. Ryu, H. S. Lim, D. R. Lee, Y.-J. Kwark and J. H. Cho, J. Mater. Chem., 2011, 21, 6968-6974.

41 Y. Jeong, C. Pearson, H.-G. Kim, M.-Y. Park, H. Kim, L.-M. Do and M. C. Petty, ACS Appl. Mater. Interfaces, 2016, 8, 20612070.

42 H. S. Lee, K. Park, J.-D. Kim, T. Han, K. H. Ryu, H. S. Lim, D. R. Lee, Y.-J. Kwark and J. H. Cho, J. Mater. Chem., 2011, 21, 6968-6974.

43 D. K. Hwang, C. Fuentes-Hernandez, J. Kim, W. J. Potscavage Jr, S. J. Kim and B. Kippelen, Adv. Mater., 2011, 23, 12931298.

44 X. Cheng, M. Caironi, Y.-Y. Noh, J. Wang, C. Newman, H. Yan, A. Facchetti and H. Sirringhaus, Chem. Mater., 2010, 22, 1559-1566.

45 T. Umeda, D. Kumaki and S. Tokito, Org. Electron., 2008, 9, 545-549.

46 C.-Y. Yang, J.-S. Chen and S. L.-C. Hsu, J. Electrochem. Soc., 2006, 153, F120-F125.

47 C. Luo, A. K. K. Kyaw, L. A. Perez, S. Patel, M. Wang, B. Grimm, G. C. Bazan, E. J. Kramer and A. J. Heeger, Nano Lett., 2014, 14, 2764-2771.

48 M. S. Kang and C. D. Frisbie, ChemPhysChem, 2013, 14, 15471552. 